TITLE:

\title{
Crustal structure in central California in relation to the Sierra Nevada
}

AUTHOR(S):

Mikumo, Takeshi

\section{CITATION:}

Mikumo, Takeshi. Crustal structure in central California in relation to the Sierra Nevada. Bulletin of the Seismological Society of America 1965, 55(1): 65-83

ISSUE DATE:

1965-02

URL:

http://hdl.handle.net/2433/193375

RIGHT:

(C) 1965, by the Seismological Society of America 


\title{
CRUSTAL STRUCTURE IN CENTRAL CALIFORNIA IN RELATION TO THE SIERRA NEVADA
}

\author{
By Takeshi Mikumo
}

\begin{abstract}
Crustal structure in central California (between the latitudes of $36^{\circ}$ and $41^{\circ} \mathrm{N}$ ) including the Sierra Nevada was studied by travel times of $P_{n}$ waves from Nevada explosions and earthquakes, dispersion of surface waves, and correlation between computed and observed gravity anomalies.

Simple two-dimensional models are presented for the structure, parameters of which are determined by least-squares from $P_{n}$ observations. Theoretical gravity distributions expected from the crustal models are computed by a two-dimensional technique and compared with Bouguer anomalies. In the preferred model, the overall crustal depths to the Moho-discontinuity beneath the Pacific coast region, the Central Valley and the Sierra Nevada are found to be about 22,26 and $43 \mathrm{~km}$, respectively, indicating a steep crustal thickening under the high mountain region. The dispersion of group velocities of Rayleigh and Love waves passing across the region was investigated from Nevada and Utah earthquakes; Love waves from the Utah earthquake give evidence in support of the derived structure.
\end{abstract}

\section{INTRODUCTION}

The crustal structure in central California has been studied by a number of geophysicists from various standpoints. Byerly (1938) first suggested the possible existence of a "mountain root" under the Sierra Nevada, on the basis of travel-time delays of $P_{n}$ waves which passed through the region. Increasing attention has since been paid to the structure under this mountain range not only for the seismological interest but also from an isostatic point of view. The conclusion put forward by Byerly, that a root of crustal rocks extends into the mantle down to a depth of not more than $40 \mathrm{~km}$ below the base of a standard crust, was supported by later observations of $P_{n}$ from natural earthquakes (Byerly, 1939; Gutenberg, 1943; Romney, 1957) and from nuclear explosions (Carder and Bailey, 1958), by the analysis of Bouguer gravity anomalies (Tsuboi, 1956; Thompson and Talwani, 1959; Oliver et al., 1961, 1963), and by seismic refraction measurements (Eaton, 1963).

It is not to be expected, however, that the use of either seismic or gravity data alone will provide a unique solution of the problem. The two kinds of information, including the dispersion of surface waves, can be effectively combined to restrict the number of possible solutions, as has already been demonstrated by Press (1960) in a geophysical study of the southern California-Nevada region.

In this paper such an analysis is made to infer the general features of the crustal structure in central California between the latitudes of $36^{\circ}$ and $41^{\circ} \mathrm{N}$ including the high mountain region of the Sierra Nevada (see fig. 1), by a combined use of travel times of $P_{n}$ waves from Nevada explosions and earthquakes, dispersion of surface waves from earthquakes in Nevada and Utah, and correlation between computed and observed gravity anomalies.

Seismic waves generated by the earthquakes and explosions are recorded at network stations in California, after having passed the Sierran region. It is to be noted here that the recording stations do not lie along a single profile, but for each shock 
are distributed over the sector of a circle with its center at the shock, as in the case of fan-shooting in seismic prospecting. This situation makes it possible to treat $P_{n}$ data from a different aspect to the usual refraction studies. The parameters specifying the strueture, which is assumed to be two-dimensional as a first approximation, are determined by least-squares from the $P_{n}$ observations.

Extensive gravity measurements, particularly those of the U. S. Geological Survey, provide powerful information about the structure in the Sierra and adjacent regions. Theoretical gravity fields are computed by a two-dimensional technique for the crustal models based on $P_{n}$ data, and compared with the Bouguer anomalies derived from the measurements.

The mountain root may be expected to effect the dispersion of Rayleigh and Love waves traveling through the Sierran region. The observed dispersion is related to

TABLE 1

Earthquakes and Explostons Used in This Paper

\begin{tabular}{|c|c|c|c|c|c|c|c|c|c|}
\hline Shock & Date & Origin Time & Latitude & Longitude & $\begin{array}{l}\text { Focal } \\
\text { Depth }\end{array}$ & $\begin{array}{l}\text { Magni- } \\
\text { tude }\end{array}$ & $\begin{array}{l}\text { Dis- } \\
\text { tance } \\
\text { from } \\
\text { BRK }\end{array}$ & $\begin{array}{l}\text { Azi- } \\
\text { muth } \\
\text { from } \\
\text { BRK }\end{array}$ & $\begin{array}{c}\text { Seismic } \\
\text { Waves Used }\end{array}$ \\
\hline Nevada & July 20,1962 & $09^{\mathrm{h}} 02^{\mathrm{m}} 08.3^{\mathrm{s}}$ & $39^{\circ} 30^{\prime} \mathrm{N}$ & $118^{\circ} 18^{\prime} W$ & $25 \mathrm{~km}$ & 5.3 & $380 \mathrm{~km}$ & $61.6^{\circ}$ & $L, R$ \\
\hline Utah & Aug. 30, 1962 & $13 \quad 35 \quad 28.7$ & 4148 & 11148 & 37 & 5.8 & 996 & 60.8 & $L, R$ \\
\hline BILBY & Sept. 13,1963 & 170000.1 & 3703.6 & 11601.8 & ${ }^{*}(528 \mathrm{~m})$ & $(6.0)$ & 557 & 97.4 & $P, R$ \\
\hline SHOAL & Oct. 26,1963 & 170000.1 & 3912.1 & 11822.7 & $*(1232 \mathrm{~m})$ & $(4.8)$ & 368 & 66.4 & $P$ \\
\hline Nevada & Mar. 22, 1964 & 163058.8 & 3846.5 & 11857.6 & 19 & 5.1 & 305 & 70.8 & $(P), L, R$ \\
\hline
\end{tabular}

* Shot elevation.

$P$ : Pn waves $\quad L$ : Love waves $\quad R$ : Rayleigh waves.

theoretical group velocity curves consistent with the most probable model inferred from $P_{n}$ and gravity.

\section{DAtA}

In table 1, the locations, origin-times, magnitudes and some other parameters of the earthquakes and explosions mentioned are tabulated. The epicenters of the Nevada earthquake of July 20, 1962 and the Utah earthquake of August 30, 1962 were taken from the preliminary determination of the USCGS. The Nevada earthquake of March 22, 1964 was located from $P_{n}$ data at 16 California stations, making use of the observed sHOAL explosion travel times. The $P_{n}$ observations from sHOAL made at the same stations yielded a computed location and origin time for SHOAL, which were $24 \mathrm{~km}$ southeast from and $3.5 \mathrm{sec}$ later than the actual values. These deviations were applied as corrections to the computed location of the 1964 earthquake.

The locations of the epicenters, shot points, and recording stations are shown in figure 1. Ten of the University of California stations equipped with Benioff shortperiod seismographs are connected to Berkeley by a telemeter system, and at the other UC stations, recordings are made photographically. The stations, BKS, BRK, ORV, and SCC are also equipped with long-period seismographs. In the two explosion experiments above and the 1964 Nevada earthquake, distinct first arrivals were recorded at most of the stations. The data obtained from BILBY explo- 
sion at the four stations of the California Institute of Technology, ISA, WDY, FTC and KRC, were incorporated in the present study. The observations relevant to this study are given in table 2. The letters $a, b$, and $c$ in table 2 (a) and 2(b) classify the accuracy of time readings. The errors for a-readings are estimated to

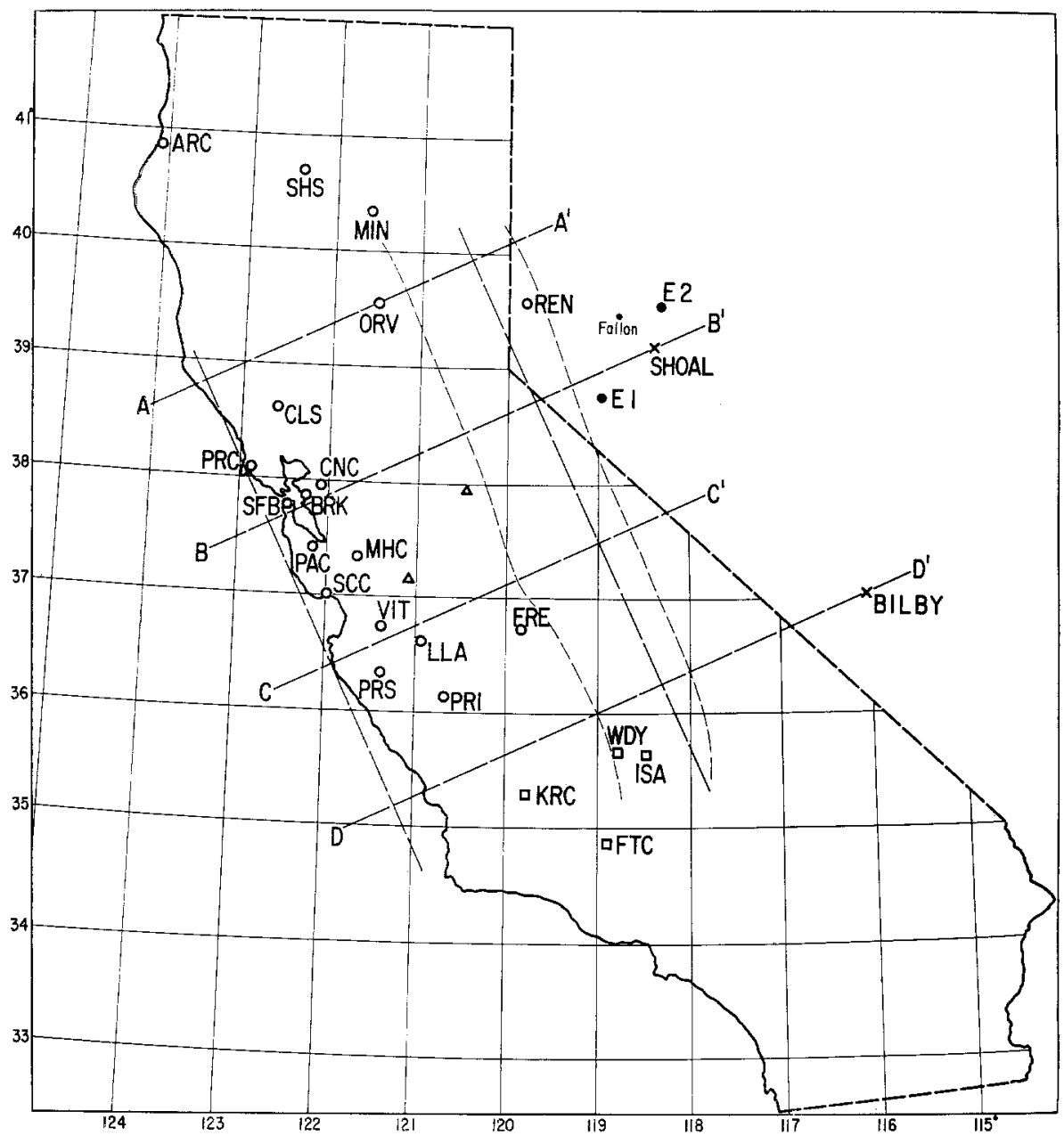

Fig. 1. Location of stations, epicenters and shot points. crosses; shot point, solid circles; earthquakes, open circles; UC stations, triangles; temporary UC stations, squares; Caltech stations whose data are used.

be less than 0.1 sec for most of telemeter and temporary stations; $b$ indicates an error of less than 0.2 sec for the other stations of this kind and for most of the local stations. An error of $0.2 \mathrm{sec}$ or more would be expected in c-readings under unfavorable circumstances.

The observed travel times were reduced to the form $T-\Delta / 8.1$, to which a correction $\delta T$ has been made for the effects of a sedimentary layer and ground sur- 
face elevation of shot point and stations. The total correction time to be subtracted would be

$$
\delta T=\left(d_{0}+d+h+h_{0}\right) \sqrt{V_{2}^{2}-V_{0}^{2}} / V_{2} V_{0}-\left(d+d_{0}\right) \sqrt{V_{2}^{2}-V_{1}^{2}} / V_{2} V_{1}
$$

where $V_{0}, V_{1}$ and $V_{2}$ are the compressional velocities in the sediment, crust and

TABLE 2(a)

Observed and Computed Travel Times of $P_{n}$ in shoal Explosion

\begin{tabular}{|c|c|c|c|c|c|c|c|c|c|}
\hline \multirow{2}{*}{ Station } & \multirow{2}{*}{ Symbol } & \multirow{2}{*}{$\begin{array}{l}\text { Distance } \\
\Delta(\mathrm{km})\end{array}$} & \multirow{2}{*}{$\begin{array}{l}\text { Azimuth } \\
\Phi \text { (deg.) }\end{array}$} & \multirow{2}{*}{\multicolumn{2}{|c|}{$\begin{array}{l}\text { Observed Travel } \\
\text { Times To (sec) }\end{array}$}} & \multirow{2}{*}{$\begin{array}{l}\text { Computed } \\
\text { Travel } \\
\text { Times Tc } \\
\quad \text { (sec) }\end{array}$} & \multicolumn{2}{|c|}{$\begin{array}{l}\text { Reduced Travel } \\
\text { Times }\end{array}$} & \multirow{2}{*}{$\begin{array}{l}\text { Residuals } \\
\text { To }-T c \\
\quad \text { (sec) }\end{array}$} \\
\hline & & & & & & & $\begin{array}{c}T o-\delta T \\
-\Delta / 8.1 \\
(\mathrm{sec})\end{array}$ & $\begin{array}{c}T c-\delta T \\
-\Delta / 8.1 \\
(\mathrm{sec})\end{array}$ & \\
\hline Reno & REN & 128.8 & 287.1 & $\mathrm{~b}$ & 22.4 & & 4.64 & & \\
\hline Jamestown $\uparrow$ & TDO & 226.8 & 232.0 & $\mathrm{a}$ & 35.1 & 35.61 & 5.54 & 6.05 & -0.51 \\
\hline Oroville & ORV & 272.1 & 278.3 & b & 40.8 & 40.81 & 5.67 & 5.68 & -0.01 \\
\hline Fresno & FRE & 297.9 & 204.6 & b & $44.8 \ddagger$ & 44.51 & 6.57 & 6.28 & 0.29 \\
\hline Mineral & MIN & 303.7 & 294.8 & $b$ & $45.2 \ddagger$ & 45.39 & 5.82 & 6.01 & -0.19 \\
\hline Quinto Ranch $\uparrow$ & $\mathrm{TCR}$ & 328.2 & 226.0 & $\mathrm{a}$ & 48.5 & 48.06 & 6.53 & 6.09 & 0.44 \\
\hline Concord* & $\mathrm{CNC}$ & 349.0 & 246.9 & $\mathrm{c}$ & 50.5 & 50.51 & 5.96 & 5.98 & -0.01 \\
\hline Mt. Hamilton* & $\mathrm{MHC}$ & 352.0 & 234.0 & a & $51.5 \ddagger$ & 51.26 & 6.22 & 5.98 & 0.24 \\
\hline Llanada* & LLA & 365.0 & 218.0 & a & 52.9 & 52.64 & 6.26 & 6.00 & 0.26 \\
\hline Berkeley B & BKS & 366.3 & 246.3 & $b$ & $52.5 \ddagger$ & 52.63 & 5.77 & 5.90 & -0.13 \\
\hline Berkeley $\mathrm{H}^{*}$ & BRK & 368.4 & 246.4 & a & 52.5 & 52.83 & 5.57 & 5.89 & -0.32 \\
\hline Calistoga ${ }^{*}$ & CLS & 369.3 & 260.2 & a & $52.5 \ddagger$ & 53.07 & 5.34 & 5.90 & -0.56 \\
\hline Vineyard* & VIT & 379.4 & 224.0 & a & 54.9 & 54.31 & 6.51 & 5.92 & 0.59 \\
\hline Shasta & SHS & 380.3 & 295.9 & $b$ & 54.3 & 54.63 & 5.83 & 6.16 & -0.33 \\
\hline Palo Alto & $\mathrm{PAC}$ & 386.6 & 239.1 & $\mathrm{c}$ & 55.5 & 55.01 & 6.32 & 5.83 & 0.49 \\
\hline San Francisco & SFB & 388.3 & 245.9 & $\mathrm{~b}$ & $54.6 \ddagger$ & 55.20 & 5.20 & 5.80 & -0.60 \\
\hline Priest* & PRI & 395.4 & 210.6 & $\mathrm{~b}$ & $56.9 \ddagger$ & 56.55 & 6.32 & 5.97 & 0.35 \\
\hline Santa Cruz* & $\mathrm{SCC}$ & 400.0 & 232.5 & $\mathrm{~b}$ & $56.4 \ddagger$ & 56.66 & 5.55 & 5.80 & -0.25 \\
\hline Pt. Reyes* & PRC & 409.3 & 252.3 & a & $57.5 \ddagger$ & 57.82 & 5.42 & 5.73 & -0.31 \\
\hline Paraiso* & PRS & 413.6 & 219.5 & a & 58.8 & 58.43 & 6.20 & 5.83 & 0.37 \\
\hline Arcata & $\mathrm{ARC}$ & 519.7 & 291.0 & $\mathrm{~b}$ & $71.8 \ddagger$ & 71.42 & 6.19 & 5.84 & 0.38 \\
\hline
\end{tabular}

* Telemeter stations; $\dagger$ Temporary stations; $\$$ Followed by 2 nd arrival.

Accuracy of time reading:

$a-\Delta T \leqq 0.1 \mathrm{sec}, b-0.1<\Delta T<0.2 \mathrm{sec}, c-\Delta T>0.2 \mathrm{sec}$.

$\delta T$-Correction for surface layer and elevation.

Tc-Computed travel times for Model 3.

mantle, respectively; $d_{0}$ and $d$ are the thicknesses of the sedimentary layer below sea level, and $h_{0}$ and $h$ are elevations of shot point and station. In the present case, the following values which were extrapolated from Healy's results (1963) were taken: $V_{1}=6.1 \mathrm{~km} / \mathrm{sec}, V_{2}=7.9 \mathrm{~km} / \mathrm{sec} ; V_{0}=3.0 \mathrm{~km} / \mathrm{sec}$ and $d=3.0 \mathrm{~km}$ for all stations in California; $V_{0}=3.5 \mathrm{~km} / \mathrm{sec}$ (Eaton, 1963) and $d_{0}=4.0 \mathrm{~km}$ were tentatively assumed for the two shot points in Nevada. This assumption for $d_{0}$ and $V_{0}$ is a modification from Eaton's model (1963) on the basis of travel times and gravity. Additional information from seismic refraction measurements made close 
to Fallon (see fig. 1) indicates that the Carson sink sediments with low velocity and density extend to a depth of $2.4 \mathrm{~km}$ (Eaton, written communication, 1964). The above assumption may be in fair agreement with this evidence.

The reduced travel times thus obtained for first arrivals from the two explosions and the Nevada earthquake of $\mathbf{1 9 6 4}$ are plotted against distance in figure 2 . The

TABLE 2(b)

Observed and Computed Travel Times of $P_{n}$ in Bilby Explosion

\begin{tabular}{|c|c|c|c|c|c|c|c|c|c|}
\hline \multirow{2}{*}{ Station } & \multirow{2}{*}{ Symbol } & \multirow{2}{*}{$\begin{array}{l}\text { Distance } \\
\Delta(\mathrm{km})\end{array}$} & \multirow{2}{*}{$\begin{array}{l}\text { Azimuth } \\
\Phi \text { (deg.) }\end{array}$} & \multirow{2}{*}{\multicolumn{2}{|c|}{$\begin{array}{c}\text { Observed } \\
\text { Travel Times } \\
\text { To (sec) }\end{array}$}} & \multirow{2}{*}{$\begin{array}{c}\text { Computed } \\
\text { Travel } \\
\text { Times Tc } \\
\quad \text { (sec) }\end{array}$} & \multicolumn{2}{|c|}{$\begin{array}{c}\text { Reduced Travel } \\
\text { Times }\end{array}$} & \multirow{2}{*}{$\begin{array}{l}\text { Residuals } \\
\text { To-Tc } \\
\quad(\mathrm{sec})\end{array}$} \\
\hline & & & & & & & $T o-\delta T$ & $T c-\delta T$ & \\
\hline Isabella $\uparrow$ & ISA & 270.8 & 234.4 & b & 40.9 & 41.81 & 5.99 & 6.90 & -0.91 \\
\hline Woodyt & WDY & 295.0 & 239.1 & b & 44.1 & 44.57 & 6.38 & 6.85 & -0.47 \\
\hline Fresno & FRE & 337.6 & 264.5 & $b$ & 49.9 & 49.79 & 6.94 & 6.83 & 0.11 \\
\hline Fort Tejon† & FTC & 355.2 & 226.8 & b & 52.0 & 51.98 & 6.81 & 6.78 & 0.03 \\
\hline Kings Ranch $\dagger$ & $\mathrm{KRC}$ & 386.2 & 240.0 & $b$ & 56.1 & 55.68 & 7.11 & 6.70 & 0.41 \\
\hline Priest* & PRI & 427.4 & 256.2 & $a$ & 61.1 & 61.01 & 6.74 & 6.66 & 0.08 \\
\hline Llanada* & LLA & 441.2 & 263.6 & a & 62.3 & 62.55 & 6.43 & 6.68 & -0.25 \\
\hline Vineyard* & VIT & 478.0 & 267.5 & a & 67.5 & 67.04 & 7.12 & 6.65 & 0.47 \\
\hline Paraiso* & PRS & 483.3 & 262.0 & a & 67.8 & 67.63 & 6.77 & 6.60 & 0.17 \\
\hline Mt. Hamilton* & MHC & 498.3 & 275.3 & $\mathrm{a}$ & 70.3 & 69.90 & 7.13 & 6.73 & 0.40 \\
\hline Santa Cruz* & $\mathrm{SCC}$ & 529.9 & 271.2 & b & 73.2 & 73.35 & 6.49 & 6.64 & -0.15 \\
\hline Concord* & $\mathrm{CNC}$ & 542.6 & 282.6 & $b$ & 75.9 & 75.07 & 7.64 & 6.81 & 0.83 \\
\hline Palo Alto & $\mathrm{PAC}$ & 546.3 & 276.0 & $b$ & 75.5 & 75.41 & 6.79 & 6.70 & 0.09 \\
\hline Berkeley B & BKS & 555.3 & 281.3 & $\mathrm{a}$ & 76.9 & 76.66 & 7.01 & 6.77 & 0.24 \\
\hline Berkeley $\mathbf{H}^{*}$ & BRK & 557.4 & 281.2 & a & 76.9 & 76.86 & 6.82 & 6.78 & 0.04 \\
\hline San Francisco & SFB & 572.9 & 279.9 & b & 78.4 & 78.75 & 6.39 & 6.74 & -0.35 \\
\hline Calistoga* & CLS & 601.8 & 288.9 & a & 82.6 & 82.60 & 6.91 & 6.92 & -0.01 \\
\hline Mineral & MIN & 606.1 & 308.7 & b & 83.8 & 84.02 & 7.26 & 7.48 & -0.22 \\
\hline Pt. Reyes* & PRC & 613.2 & 282.7 & a. & 83.7 & 83.84 & 6.63 & 6.76 & -0.13 \\
\hline Shasta & SHS & 682.7 & 308.2 & $b$ & 92.8 & 93.15 & 7.18 & 7.53 & -0.35 \\
\hline
\end{tabular}

* Telemeter stations.

$\uparrow$ Caltech stations.

travel times of the arrivals are expressed in the following equations determined by least-squares from 20 measurements:

$$
\begin{aligned}
& T=\Delta /(8.06 \pm 0.03)+5.70 \pm 0.80 \text { for SHOAL } \\
& T=\Delta /(8.01 \pm 0.02)+6.12 \pm 0.54 \text { for BILBY }
\end{aligned}
$$

The apparent velocities which are in excess of $8.0 \mathrm{~km} / \mathrm{sec}$ found in both cases indicate that the first arrivals may be identified as $P_{n}$ waves, but the values are only an average over a wide area, because the stations do not lie on a line. The difference in $P_{n}$ intercept times between sHOAL and BILBY might be explained by the difference in crustal and sedimentary thicknesses at the two shot points. The smaller intercept 
in the Nevada earthquake (fig. 2) is a result of the focus being deep in the crust at 19 kilometers. At the stations marked by dots in the fifth column in table 2(a), second arrivals of larger amplitude were observed, which in the case of sHOAL have an apparent velocity of about $6.3 \mathrm{~km} / \mathrm{sec}$ and an intercept time of 1.4 seconds. The velocity may be interpreted as that of $P_{g}$, but more observations are needed for a firm conclusion. The corresponding phases could not be obtained from BILBY because of large motion after the first arrivals.

In fig. 3 the reduced travel times are plotted as a function of azimuth, being measured clockwise from north at each shot point. It can be seen that there is a significant curvature in the time-azimuth relation for the two explosions as well as for the Nevada shock of 1964. There could be several explanations for the trend.

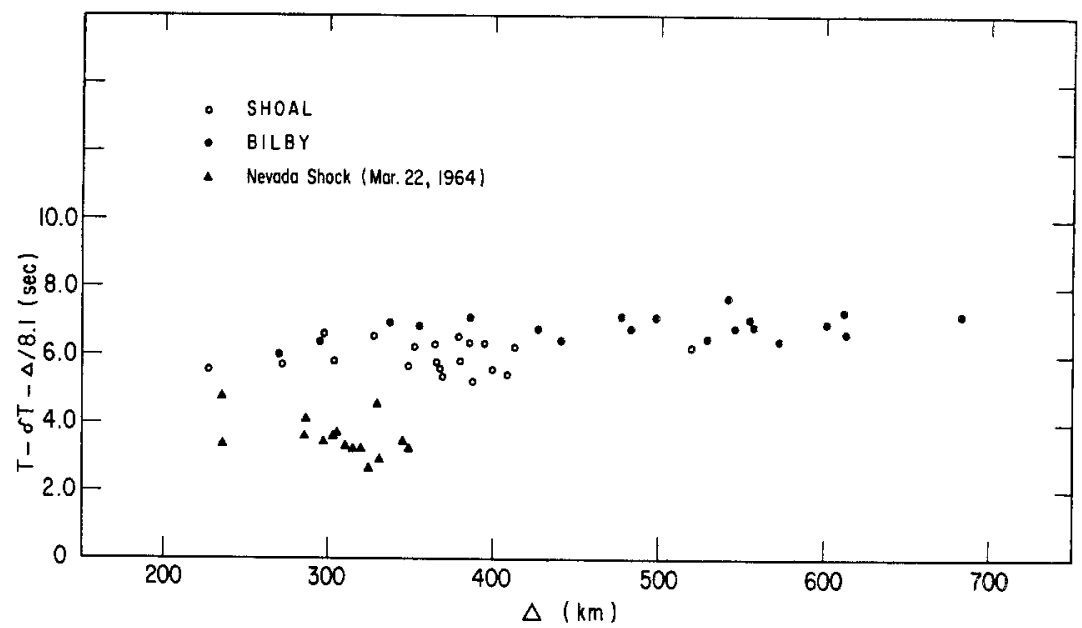

FIG. 2. Reduced travel times versus distance. solid circles; SHOAL data, open circles; BILBY data, triangles; data from the Nevada shock of Mareh 22, 1964.

This common trend is unlikely to be caused simply by local velocity irregularities or variation in crustal thickness beneath the stations, because some stations with delayed travel times from SHOAL and the earthquake mentioned also fall on a group of shorter travel times from BILBY. A possible explanation, if TDO, ORV, MIN, SHS, ARC, ISA and WDY are excluded, is that a thicker crust beneath a limited region in the central Sierra would cause late arrivals from sHOAL at stations south of $\mathrm{MHC}$; there would not be comparative effects on travel times in the case of BILBY. Another possibility is that the trend could come from an azimuthal difference in the thin crust near the sHOAL shot point, if the same, but a little smaller, trend for BILBY is neglected. These possibilities cannot be rejected solely on the basis of the travel times. However, the results derived from these hypotheses introduce difficulties with regard to the observed gravity anomaly distribution. For this reason, the trend was interpreted from a different point of view.

An azimuth of 240-250 degrees, where the reduced times show a minimum, is almost perpendicular to the general direction of the Sierra range. It may be inferred that $P_{n}$ waves are delayed at the northern and southern stations, compared with the waves passing perpendicularly through the Sierra Nevada. This agrees essen- 
tially with Byerly's findings (Byerly, 1939). It has also been stated by Romney (1957), in his study of the Fairview Peak earthquake of Dec. 16, 1954, that there seems to be a correlation between the delay time and the length of the wave path under the high mountain region.

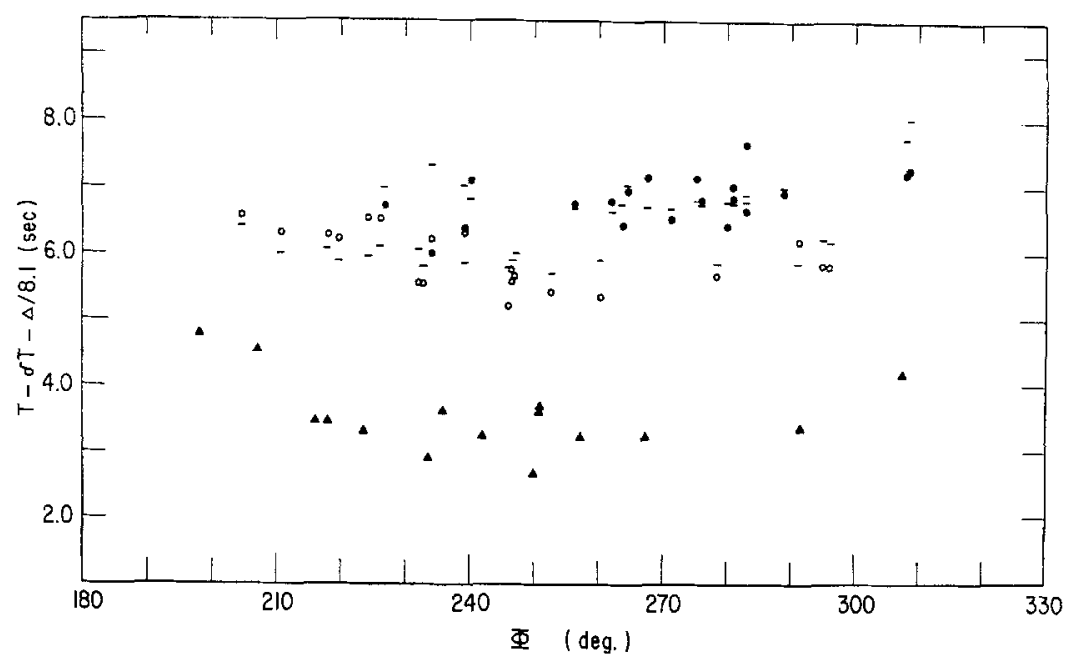

FIG. 3. Reduced travel times versus azimuth.-; computed values.

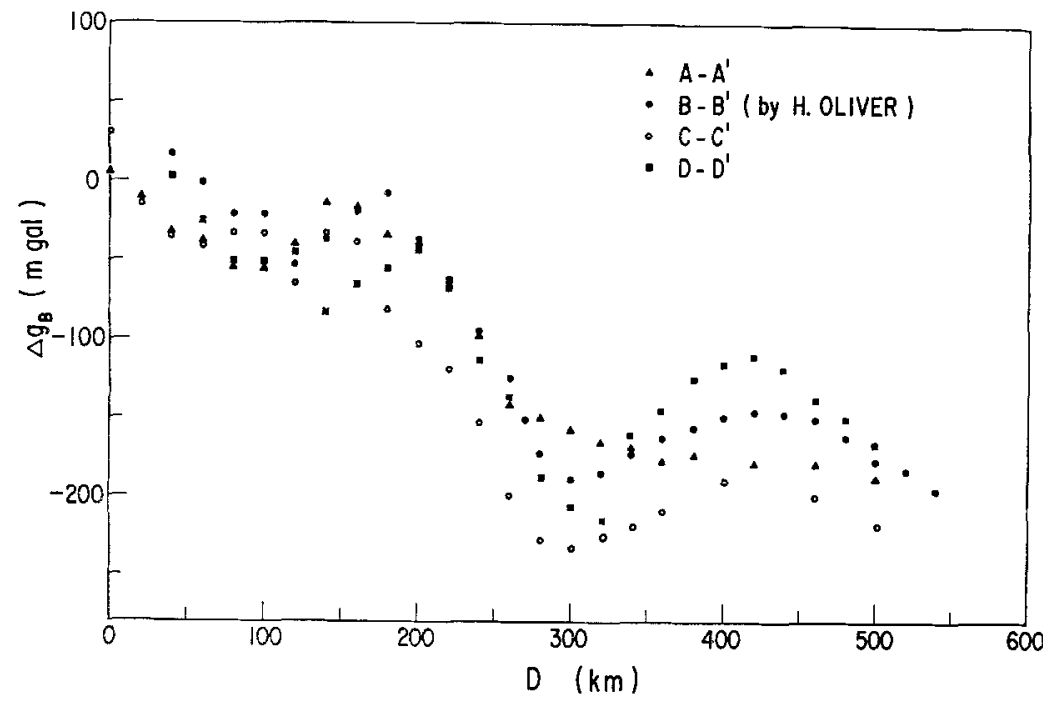

FIG. 4. Bouguer anomaly distribution along four profiles.

Figure 4 shows the Bouguer gravity anomalies spaced at every $20 \mathrm{~km}$ along four profiles marked in fig. 1, taken nearly normally to the Sierra range. The anomalies along $B-B^{\prime}$ were compiled by $H$. W. Oliver (written communication, 1964) from data obtained by the U.S. Geological Survey; the other values were mainly taken by interpolation from a simple Bouguer gravity map compiled by the Division of 
Mines and Geology of the State of California, based on the work of Woollard and Rose (1963). There are slight differences in the anomalies between the four profiles, but the general trend is a decrease from the coast to the Sierra region; to the east of the Sierra the anomalies increase towards Nevada. This tendency allows the assumption that the structure is approximately two-dimensional.

\section{Crustal Models from $P_{n}$}

Some of the previous work gave ideas of the shape of the mountain root in the Sierran region. Byerly (1938) estimated the breadth of the Sierran batholith at a depth of $30 \mathrm{~km}$ to be 40 to 70 kilometers. Oliver et al. (1961) have associated the variation in the regional Bouguer anomalies with a crustal thickening beneath the

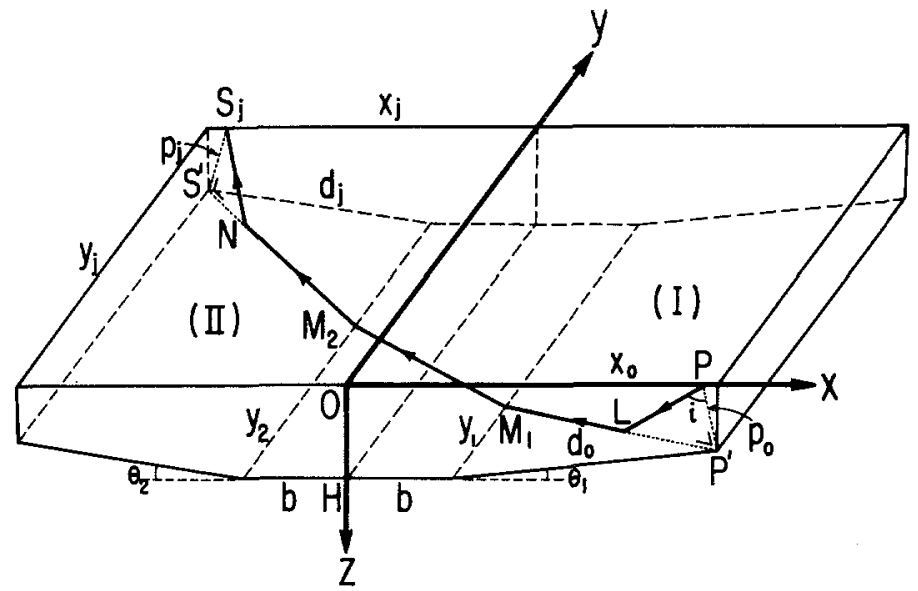

Fig. 5. A crustal model.

central Sierra, and stated that the base of the crust dips toward the central Sierra crest at an angle of $27^{\circ}$ in the Yosemite region on both the west and east flanks. From recent refraction measurements made along a reversed profile between San Francisco and Fallon, Nevada, Eaton (1963) found that the Moho-discontinuity must dip eastward at nearly $11^{\circ}$ in the region of Lake Tahoe continuing to a depth of 40 to $45 \mathrm{~km}$, and that the crust thins abruptly towards the Basin and Range province.

Taking these circumstances and the Bouguer anomaly distribution in fig. 4 into consideration, we assume a simplified two-dimensional model composed of a crust and mantle, as shown in fig. 5, as a first approximation for the structure. The azimuthal dependence of the travel times shown in figure 3 may be interpreted as a consequence of such a model.

Suppose that the thickest portion of the crust, geometrically like a horizontally truncated wedge, occurs somewhere beneath the Sierra, and that the crust thins with a uniformly dipping Moho-discontinuity towards the coastal region and the Basin and Range province. We take the $y$-axis in the ground surface, parallel to the direction of intersection which would be formed by the two dipping interfaces, the $x$-axis normally to $y$, including the shot point on this axis. The $z$-axis is taken down- 
ward. The minimum travel-time path from the shot point $P$ to a station $S_{j}$ may be such as shown in figure 5 . Since these are diffracted $P_{n}$ waves, the transmitted energy should be small, depending on the angles of the edges. However, if we introduce a small velocity gradient in the upper mantle beneath the bottom, the waves can be refracted back to the station, grazing the two edges. This case may well be approximated by the former one.

By finding the positions of $L, M_{1}, M_{2}$, and $N$, we have the travel-time equation for the minimum-time path as a function of both distance and azimuth: i.e.

$$
T=\left(p_{0}+p_{j}\right) \cos i / V_{1}+\sqrt{\left(2 b+d_{0}+d_{j}\right)^{2}+y_{j}^{2}} / V_{2}
$$

where $\sin i=V_{1} / V_{2}$

$$
\begin{aligned}
& p_{0}=h \cos \theta_{1}-\left(x_{0}-b\right) \sin \theta_{1}, d_{0}=h \sin \theta_{1}+\left(x_{0}-b\right) \cos \theta_{1} \\
& p_{j}=h \cos \theta_{2}-\left(x_{j}-b\right) \sin \theta_{2}, d_{j}=h \sin \theta_{2}+\left(x_{j}-b\right) \cos \theta_{2}
\end{aligned}
$$

and

$$
x_{j}=\Delta_{j} \cos \phi_{j}-x_{0}, y_{j}=\Delta_{j} \sin \phi_{j}, \phi_{j}=\Phi_{0}-\Phi_{j} .
$$

$V_{1}$ and $V_{2}$ are the velocities in the crust and mantle respectively, $x_{0}$ is the horizontal distance between the shot point and the $y$-axis, $\Phi_{0}$ is the orientation of the $y$-axis, $h$ is the depth to the crustal bottom, $2 b$ is the breadth of the bottom, and $\theta_{1}$ and $\theta_{2}$ are the dips of the Moho-discontinuity. For $b=0$, the formula reduces to that for a simple wedge.

As can be seen in the models of Eaton and Oliver et al., the Moho-discontinuity does not maintain a uniform dip, but changes its gradient towards the coast and Nevada. For the stations beyond the inflection point, the minimum travel-time path does not go along the discontinuity between the crust and mantle. However, the above equations hold also in this case by replacing $\theta_{1}$ and $\theta_{2}$ with the appropriate dips and by adding a correction term, since the incident angle of a seismic ray into the discontinuity is not very far from $90^{\circ}$. This case is later designated as Model 3.

The unknown parameters in the above equations were determined from the observed travel times. The square sum of $O-C$ residuals, $E=\sum_{k=1}^{n}\left(T o^{(k)}-T c^{(k)}\right)^{2}$, where $T o^{(k)}$ and $T c^{(k)}$ are the observed and computed travel times at the $k$-th station, was minimized numerically by successive iteration of the parameters on a computer. Each of the variables was successively varied in turn within a previously estimated possible range to look for a minimum of $E$, setting the other parameters to adopted starting values. The starting values were taken from the work mentioned in the foregoing sections and also from topography of the Sierra Nevada. Once a value of the variable was found for which $E$ is a minimum, the variable was fixed to the value instead of its starting one. The whole procedure was repeated until ultimate convergence was reached, in which $E$ has an absolute minimum within the defined domain.

The computation was done by an IBM 7090 computer for each of sHoAL and 
BILBY cases separately, assuming four types of crustal model; Model 1 having a wedge-shaped crust (the case of $b=0$ ), Model 2 with a crust of horizontally truncated wedge at the bottom, Model 3, a modification of Model 2, and Model 4 in which all parameters were equal to those in Eaton's model. In Models 1 and 4, a sedimentary layer with a constant thickness of $1.5 \mathrm{~km}$ and a velocity of $3.5 \mathrm{~km} / \mathrm{sec}$ was assumed to lie over the profile. The computed parameters and standard deviation of travel times $(\sigma=\sqrt{E / N})$ for these models are listed in table 3 . The values computed from SHOAL explosion are believed to be more reliable than those from BILBY, because of the more symmetrical distribution of stations in the former case (see figure 1). It can be said from the standard deviations for sHoAL that Model 3

TABLE 3

\begin{tabular}{|c|c|c|c|c|c|c|}
\hline \multirow{2}{*}{ Parameters } & \multirow{2}{*}{$\begin{array}{l}\text { Model } 1 \\
\text { SHOAI }\end{array}$} & \multicolumn{2}{|c|}{ Model 2} & \multicolumn{2}{|c|}{ Model 3} & \multirow{2}{*}{$\begin{array}{l}\text { Model } 4^{*} \\
\text { SHOAL }\end{array}$} \\
\hline & & SHOAL & BILBY & SHOAL & BILBY & \\
\hline$\Phi_{0}(\operatorname{deg}.) \ldots$ & 333 & 336 & 334 & 336 & 336 & 333 \\
\hline$x_{0}(\mathrm{~km}) \ldots \ldots$ & 136 & 118 & 228 & 104 & 196 & 104 \\
\hline$h(\mathrm{~km}) \ldots$. & 42.0 & 40.5 & 40.5 & 43.0 & 43.0 & 40.0 \\
\hline $2 b(\mathrm{~km}) \ldots$ & 0 & 40 & 30 & 56 & 50 & 110 \\
\hline$\theta_{1}$ (deg.) .... & 12.8 & 18.9 & & 20.0 & & 23.2 \\
\hline$\theta_{1}^{\prime}$ (deg.) .... & & & 6.0 & & 4.8 & 0.0 \\
\hline$\theta_{2}$ (deg.)... & 3.2 & 3.0 & 2.5 & 12.0 & 14.0 & 10.7 \\
\hline$\theta_{2}^{\prime}$ (deg.) ..... & & & & 3.0 & 3.0 & 0.0 \\
\hline$V_{1}(\mathrm{~km} / \mathrm{sec})$ & 6.03 & 6.19 & 6.28 & 6.34 & 6.26 & 6.00 \\
\hline$V_{2}(\mathrm{~km} / \mathrm{sec})$ & 7.87 & 7.91 & 7.93 & 7.95 & 7.90 & 7.90 \\
\hline$\sigma(\sec ) \ldots \ldots$ & 0.411 & 0.415 & 0.373 & 0.379 & 0.371 & 0.721 \\
\hline
\end{tabular}

* Parameters are equal to the values in Eaton's model (1963).

is the most acceptable one. The computed travel times at each station for this model are given in table 2(a) and 2(b), and also shown in figure 3 . The conclusion is that it has been able to explain the azimuthal dependence of the travel times by the adopted two-dimensional model. The numerical computations show that the timeazimuth relation depends more on the dip angle $\theta_{2}$ and ${\theta_{2}}^{\prime}$ than on the crustal depth $h$.

Probable errors in the estimated parameters cannot be obtained in the usual way, since the problem is not a linear least-squares one. Each of the time readings has an expected error $\Delta T_{j}$ as indicated in table 2. Several extreme cases were considered in which the total time errors were a maximum; for example, the case when the travel times are $T_{j}+\left|\Delta T_{j}\right|$ or $T_{j}-\left|\Delta T_{j}\right|$ instead of $T_{j}$ for all stations. The same computation described above has been made for these cases. The maximum variations estimated for the parameters are: $1 \mathrm{~km}$ in $h, 4 \mathrm{~km}$ in $b, 8 \mathrm{~km}$ in $x_{0}$, $0.7^{\circ}$ in $\theta_{1}, \theta_{2}, \theta_{1}{ }^{\prime}$ and $\theta_{2}{ }^{\prime}, 0.03 \mathrm{~km} / \mathrm{sec}$ in $V_{1}$ and $V_{2}$, and $3^{\circ}$ in $\Phi_{0}$.

\section{Computation of Gravity Distribution}

The appropriateness of the specific crustal models derived from $P_{n}$ observations is now tested by the distribution of observed gravity anomalies. The results obtained 
by Tsuboi (1956), Thompson and Talwani (1959) and Oliver et al. (1961) from Bouguer gravity values indicate that the thickness of the crust could reach $50 \mathrm{~km}$ or more under the Sierran region. This is significantly larger than the thickness derived from the seismic data in the present paper. Interpretation of gravity data alone depends on the assumed crustal-layering, density contrasts and surface geology. If the crustal parameters have been determined from seismic observations, the gravity distribution expected from the structure can be computed and compared with Bouguer anomalies.

There exist several methods for computing the gravitational attraction due to two-dimensional bodies of arbitrary shape. In the present study we use the computation technique developed by Talwani and others (1959), in which the vertical and horizontal components of the attraction can be obtained by a line integral taken along the periphery of a two-dimensional body being approximated by a polygon. Their solution has been modified in the present case. Suppose that we have $m$ crustal layers (including the mantle), the $j$-th of which being $n_{j}$-sided polygon. Let the coordinates of the $k$-th edge in the $j$-th layer be $\left(x_{j, k}, z_{j, k}\right)$ and the density of the layer be $\rho_{j}$. The vertical component $V$ of gravitational attraction due to the whole layers can be expressed in a general form:

$V=2 G \sum_{j=1}^{m} \rho_{j} \sum_{k=1}^{n_{j}}\left(x_{j, k+1} \Delta z_{j, k}-z_{j, k+1} \Delta x_{j, k}\right)\left\{-\Delta \theta_{j, k} \Delta x_{j, k}+\Delta z_{j, k} \log _{e}\left(r_{j, k+1} / r_{j, k}\right)\right\} / \Delta r_{j, k}^{2}$

where

$$
\begin{gathered}
\Delta x_{j, k}=x_{j, k+1}-x_{j, k}, \quad \Delta z_{j, k}=z_{j, k+1}-z_{j, k} \\
\Delta \theta_{j, k}=\theta_{j, k+1}-\theta_{j, k}=\tan ^{-1}\left[\left(z_{j, k+1} x_{j, k}-z_{j, k} x_{j, k+1}\right) /\left(x_{j, k+1} x_{j, k}+z_{j, k+1} z_{j, k}\right)\right] \\
r_{j, k}^{2}=x_{j, k}^{2}+z_{j, k}^{2}, \quad \Delta r_{j, k}^{2}=\Delta x_{j, k}^{2}+\Delta z_{j, k}^{2}
\end{gathered}
$$

and $G$ is the universal gravitational constant. If the computation is made for each of the points spaced at a finite interval of $d$, the attraction $V_{i}$ at the $i$-th point is obtained by substituting $x_{j, k(i)}=x_{j, k(0)}-d \cdot i$ for $x_{j, k}$. The theoretical gravity anomalies $\Delta g_{i}$ are given by $\Delta g_{i}=V_{i}-V_{0}$, subtracting a constant $V_{0}$ from the above expression. $V_{0}$ means the vertical attraction caused by the assumed standard structure consisting of the horizontal crust and mantle with known depths and densities. The base of the mantle in the assumed structure is fixed to the same depth as used in the computation of $V$. The thickness of the crust in the reference structure was taken to be $28 \mathrm{~km}$, which is the average over the profile now investigated.

Densities of the crustal layers can be evaluated from empirical relations between compressional velocity and density, of Nafe and Drake (Talwani et al., 1961), Woollard (1959), and Birch (1961). In the present case, densities of 2.80 and $3.25 \mathrm{~g} / \mathrm{cm}^{3}$ were assigned for the crust and mantle respectively, taking average values from the three relations for velocities of 6.30 and $7.95 \mathrm{~km} /$ sec. Average 
densities from the former two relations were applied to surface layers with velocities lower than $5.6 \mathrm{~km} / \mathrm{sec}$.

The gravity anomaly distribution was computed by an IBM 7090 computer for the four models derived from seismic data. The effects due to sedimentary layers and an unconsolidated sediment of $2.05 \mathrm{~g} / \mathrm{cm}^{3}$ under the Pacific ocean were also taken into account. In Model 1 a sedimentary layer with a constant thickness of $1.5 \mathrm{~km}$ and a density of 2.40 is assumed to lie over the profile. In order to look at more local details in surface layers, the following assumptions were made in Models

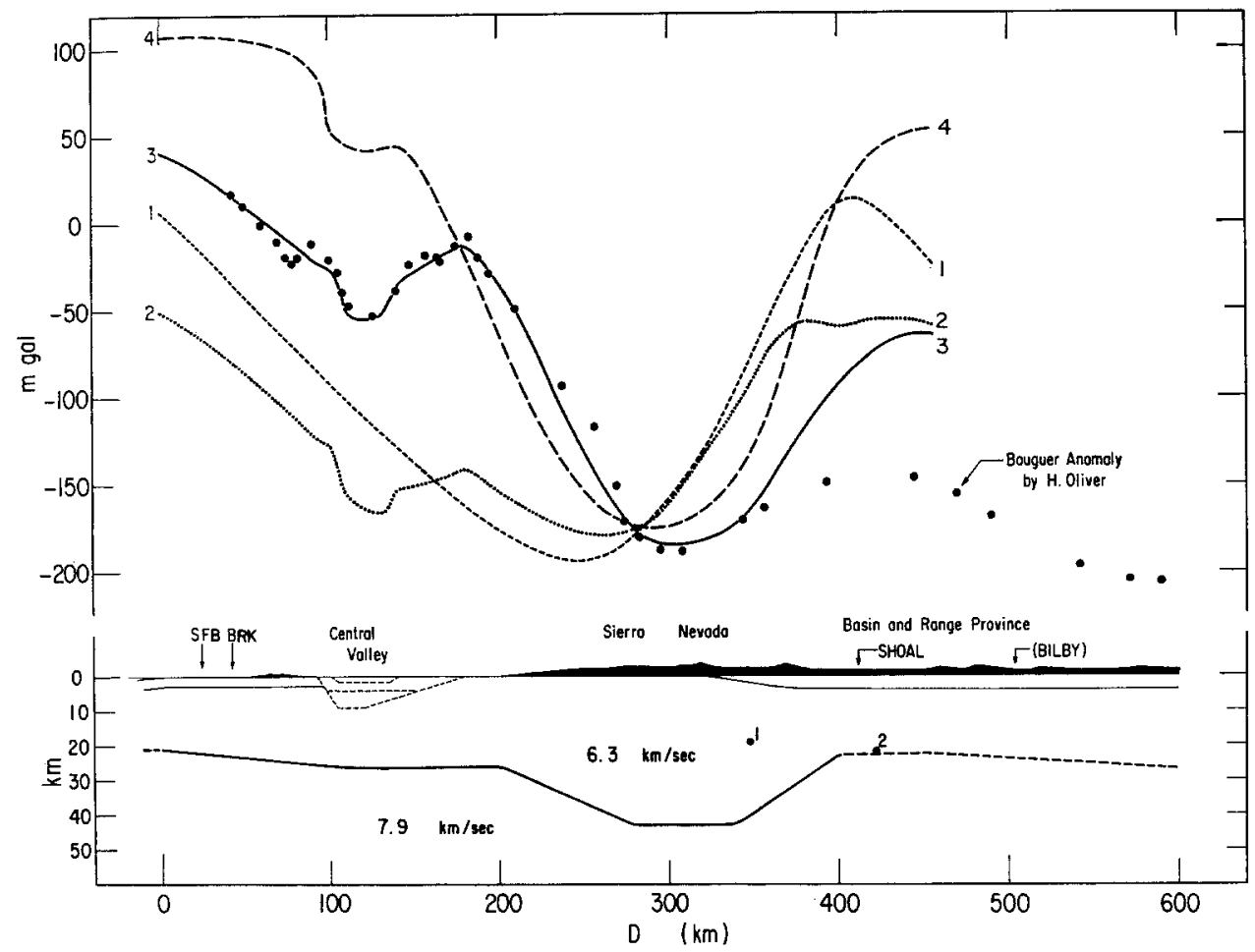

FIG. 6. Crustal structure (cross-section along $B-B^{\prime}$ ) and computed gravity curves and Bouguer anomalies.

2 and 3. A surface layer with a density of 2.40, probably of Franciscan formation, lies with thickness of $3 \mathrm{~km}$ from the coast to the western edge of the Central valley, as was assumed in the calculation from $P_{n}$. The depths of sedimentary deposits in the Central Valley have been estimated from geological evidence (cited by Oliver and Mabey, 1963; Eaton, 1963). Densities and thicknesses were taken to be 2.30 $\mathrm{g} / \mathrm{cm}^{3}$ and $1.5 \mathrm{~km}$ for the Quarternary, 2.55 and $2.5 \mathrm{~km}$ for the Tertiary, and 2.70 and $5 \mathrm{~km}$ for the Upper Cretaceous deposits. Since the direct information on the crustal depth just beneath the Central Valley cannot be obtained from $P_{n}$ observations in Model 3, a horizontal discontinuity with a depth of $26 \mathrm{~km}$ was tentatively assumed. The central Sierra Nevada is largely composed of granitic rocks of the Sierra batholith with densities ranged from 2.64 to $2.76 \mathrm{~g} / \mathrm{cm}^{3}$ (Oliver et al., 1961), 
but it is supposed from the velocity of $P_{g}$ generated by sHOAL that the density will reach below sea level the usually adopted value for the crust. For this reason the computation has not been made for the surface rocks in this region. In the Basin and Range province a sedimentary layer of the Cenozoic and pre-Tertiary deposits with a thickness of $4 \mathrm{~km}$ and a density of 2.40 was assumed to overlie the crust. This is a tentative assumption which may be in need of modification when detailed data for this region are available.

The computed gravity distributions obtained for the four models are shown in figure 6, together with Bouguer anomalies which have been compiled by Oliver (written communication, 1964). The considerable discrepancies between the computed and observed values found for Models 1 and 2 indicate that the crustal thicknesses estimated in these models are too large in California. On the other hand, Model 3 gives close agreement except towards the Basin and Range province. The cross-section of Model 3 along a profile $B-B^{\prime}$ (see figure 1) is shown in the lower part of figure 6 .

\section{Dispersion of Surface Waves}

It has been shown (Evernden, 1954; Press, 1956) that the use of phase velocities across tripartite nets can give much more local details on crustal structure than group velocity observations. In the present case the lack of sufficient stations with long-period instruments forces us to rely on group velocity technique. The mountain root might be expected to give measureable effects on the group velocity of surface waves traveling through the region.

Surface waves from the Nevada earthquakes of July 20, 1962 and March 22, 1964 and the Utah earthquake of August 30, 1962, which must have passed nearly normally across the Sierra Nevada, were recorded by long-period seismographs at Berkeley. The group velocities of Rayleigh waves determined from the vertical component records of Sprengnether $\left(T_{0}=30 \mathrm{sec}, T_{g}=100 \mathrm{sec}\right)$, Press-Ewing $\left(T_{0}=30 \mathrm{sec}, T_{g}=90 \mathrm{sec}\right)$ and Galitzin $\left(T_{0}=12 \mathrm{sec}, T_{\theta}=12 \mathrm{sec}\right)$ seismographs are plotted in fig. 7 , together with dispersion data from BILBY explosion. The three points plotted in a period range from 18 to 26 sec were obtained from a filtered seismogram. The corresponding Love wave dispersion is shown in figure 8 , which was measured mainly from the $N S$ records of a Press-Ewing and an ultra-long-period $\left(T_{0}=30 \mathrm{sec}, T_{g}=300 \mathrm{sec}\right)$ seismograph, on which the waves had a predominant component. At Reno station on the eastern flank of the Sierra Nevada, Rayleigh and Love waves from the Utah earthquake were recorded with a Press-Ewing type seismograph. The determined group velocities are also plotted in figures 7 and 8 to compare with those obtained at Berkeley.

Theoretical studies of surface waves across a structure of varying layer thickness with a sinusoidal interface have been made for Rayleigh waves (Kuo and Nafe, 1962) and for Love waves (De Noyer, 1961; R. Satô, in preparation). For a more complicated structure with undulating interfaces, an approximate expression of group velocity can be obtained from the solution for a structure of uniformly sloping interface (R. Satô, personal communication). It would be difficult however to apply these theories directly to the present case, which has a rather steeply varying crust and overlying sediments with various thicknesses over the profile. 
The alternative adopted here was to divide the entire profile into four sections, each being assumed to consist of several horizontal layers, for which the corresponding theoretical dispersion can be computed by the usual method. The composite group velocity curve expected for this profile may be obtained by $\Delta / U=$ $\sum_{j} \Delta_{j} / U_{j}$, where $\Delta=\sum_{j} \Delta_{j} . \Delta_{j}$ was tentatively assigned so that the area formed by two adjacent rectangular vertical sections may have the same value as in Model 3 for the corresponding portion. Various parameters assigned in each section are shown in table 4 . The theoretical dispersion curves for this composite model are

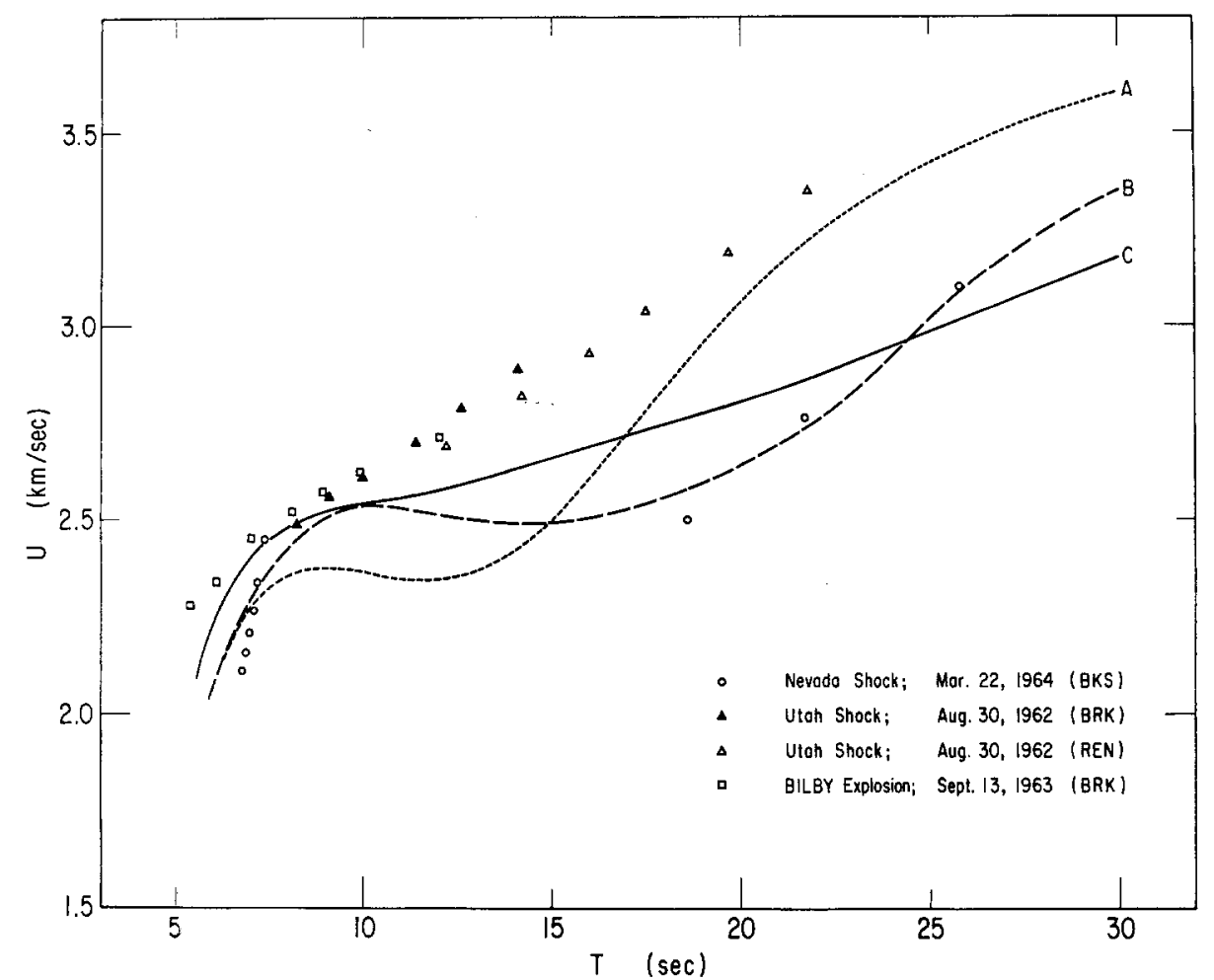

Frg. 7. Group velocities of Rayleigh waves.

shown as $C$ in figure 7 for Rayleigh waves and in figure 8 for Love waves. The curves designated $A$ and $B$ in these figures were derived from the first section in table 4 and an assumed section $\left(h_{1}=3 \mathrm{~km}, h_{2}=26 \mathrm{~km}\right)$ respectively. These sections correspond to an approximate structure beneath Berkeley and an average structure for this profile.

The observed values for both Rayleigh and Love waves from the two Nevada earthquakes whose foci are in the deep crust (see figure 6) do not fall on the composite curve $C$ but rather on curve $B$ or $A$. This seems to indicate that the surface waves were subject to the effect of the path west of the Sierra Nevada rather than that of the entire path. It was decided, therefore, to study dispersed waves whose source was distant from the Sierra range. 


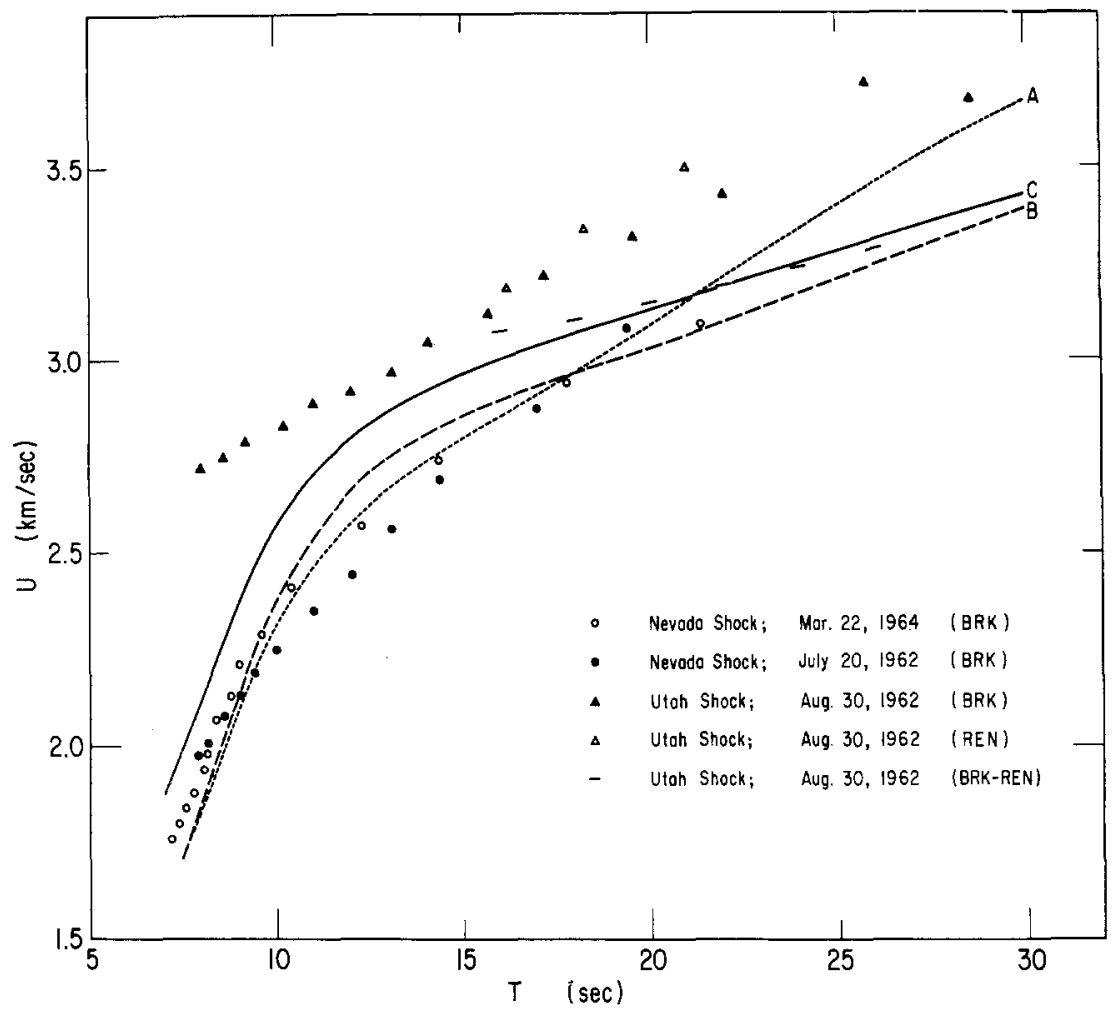

FIG. 8. Group velocities of Love waves.

TABLE 4

Parameters of Horizontally Layered Structure

\begin{tabular}{|c|c|c|c|c|c|c|c|c|c|c|c|c|c|c|c|}
\hline \multicolumn{4}{|c|}{$\Delta_{1}=60$} & \multicolumn{4}{|c|}{$\Delta_{2}=52$} & \multicolumn{4}{|c|}{$\Delta_{3}=113$} & \multicolumn{4}{|c|}{$\Delta_{1}=105$} \\
\hline$h$ & $V_{p}$ & $V_{s}$ & $\rho$ & $h$ & $V_{p}$ & $V_{s}$ & $\rho$ & $h$ & $V_{p}$ & $V_{s}$ & $\rho$ & $h$ & $V_{p}$ & $V_{s}$ & $\rho$ \\
\hline 3.0 & 3.00 & 1.70 & 2.40 & 1.5 & 2.30 & 1.33 & 2.30 & 3.0 & 3.00 & 1.70 & 2.40 & 3.0 & 5.00 & 2.90 & 2.70 \\
\hline 20.0 & 6.00 & 3.50 & 2.80 & 2.5 & 5.00 & 2.90 & 2.55 & 27.0 & 6.00 & 3.50 & 2.80 & 43.0 & 6.00 & 3.50 & 2.80 \\
\hline$\infty$ & 7.90 & 4.60 & 3.25 & 5.0 & 5.60 & 3.25 & 2.70 & $\infty$ & 7.90 & 4.60 & 3.25 & $\infty$ & 7.90 & 4.60 & 3.25 \\
\hline & & & & 17.0 & 6.00 & 3.50 & 2.80 & & & & & & & & \\
\hline & & & & $\infty$ & 7.90 & 4.60 & 3.25 & & & & & & & & \\
\hline
\end{tabular}

$\Delta_{j}$ in $\mathrm{km}, h$ in $\mathrm{km}, V_{p}$ and $V_{s}$ in $\mathrm{km} / \mathrm{sec}$, and $\rho$ in $\mathrm{g} / \mathrm{cm}^{3}$.

The group velocities observed at Berkeley of Love and Rayleigh waves from the Utah earthquake of 1962 and those of Rayleigh waves from BILBY are significantly higher than those from the two Nevada shocks. The Love waves from the Utah earthquake observed at Reno show higher velocities than those at Berkeley for periods longer than 15 seconds. These facts suggest that the average crustal thickness in the Basin and Range province is shallower than that west of Reno. In order to eliminate the effect of structure in the province, the group velocities of Love waves $U_{B-R}$ to be expected for the path west of Reno were calculated by $U_{B-R}=$ 
$\left(\Delta_{B}-\Delta_{R}\right) /\left(\Delta_{B} / U_{B}-\Delta_{R} / U_{R}\right)$ from data observed at Berkeley and Reno in the Utah earthquake. The calculated velocities for periods from 16 to 26 sec shown in figure 8 by a dotted line fall closely on the composite theoretical curve $C$. It may be said from this evidence that Model 3 is supported also by the dispersion of Love waves. There is no corresponding information from Rayleigh waves because of the lack of observational data.

It is to be noted that the shear velocity in the crust was taken as $3.5 \mathrm{~km} / \mathrm{sec}$ in the above computation of theoretical dispersion curves, rather than $3.6 \mathrm{~km} / \mathrm{sec}$ which is obtained from a compressional velocity of $6.3 \mathrm{~km} / \mathrm{sec}$ with Poisson's ratio of $1 / 4$. If $3.6 \mathrm{~km} / \mathrm{sec}$ is adopted, all theoretical curves are displaced by about $3 \%$ to higher velocities.

\section{Discussion}

Evidence has been given that Model 3 is a satisfactory approximation to the crustal structure in the area investigated.

The average crustal depth beneath the Pacific coastal region was found to be about $22 \mathrm{~km}$, which agrees within the uncertainties with other results from seismic refraction measurements (Healy, 1963; Hamilton el al., 1964). The crust thickens with a dip of about $3^{\circ}$ to a point under the Central Valley. To satisfy the gravity data, the crust then has a nearly constant depth of $26 \mathrm{~km}$ to the western edge of the Sierra Nevada, although there is no definite evidence on this point from $P_{n}$ observations. Although the dip is strongly related to the azimuthal dependence of travel times of $P_{n}$, the uncertainty of the calculated dip would allow the crust to be thicker by $1.5 \mathrm{~km}$ under the west part of the Valley and to thin slightly toward the west edge of the Sierra. The computed gravity distribution based on this new assumption does not indicate a serious discrepancy from the observed values. There is support for the assumption also from the large negative travel-time residuals at the four stations located in this region, MIN, TDO, ISA, and WDY.

Eaton's results (1963) show a generally thinner crust compared with Model 3 on account of lower crustal velocity. In the present model the Moho-discontinuity dips from the east side of the Central Valley eastward with a rather steep angle of $12^{\circ}$, reaches a depth of $43 \mathrm{~km}$ beneath the central Sierran region, and goes up with a dip of $20^{\circ}$ to $22 \mathrm{~km}$ under the west Basin and Range province. It is likely that the dip at the eastern flank is steeper than that at the west side, but this does not agree with the Bouguer gravity distribution. The breadth of the crustal bottom may be of order of $60 \mathrm{~km}$. The average shape of the mountain root given by the present analysis is somewhat different from that in Eaton's model and generally shallower than Oliver's (Oliver et al., 1961). The difference is not unexpected, considering that the present model is a simplified two-dimensional one averaged over some distance along the long axis of the Sierra range.

The velocity of $7.95 \mathrm{~km} / \mathrm{sec}$ (table 3) obtained from the sHOAL data is an average mantle velocity over the present profile. There is a possibility, as suggested by Eaton (written communication, 1964), that a $P_{n}$ velocity higher than $8.0 \mathrm{~km} / \mathrm{sec}$ extends from the Pacific coast as far as the bottom of the Sierra root and could change to $7.8 \mathrm{~km} / \mathrm{sec}$ towards the Basin and Range province. It does not appear, 
however, that a flat Moho-discontinuity from the coast to the western edge of the Sierra is supported by the gravity distribution.

The crustal velocity of $6.3 \mathrm{~km} / \mathrm{sec}$, which was found by the present computation and also confirmed by $P_{g}$ from sHoAL, is a little higher than the usually inferred values for $P_{q}$ (Healy, 1963: Eaton; 1963). A possible explanation is that the higher velocity occurs at depths deeper than a few kilometers, while the lower velocity is associated with the upper crustal boundary. The velocity of $6.3 \mathrm{~km} / \mathrm{sec}$ gives a corresponding shear velocity of $3.6 \mathrm{~km} / \mathrm{sec}$ if Poisson's ratio of $1 / 4$ is adopted. In order to get a closer agreement between the observed and computed group velocities of the surface waves mentioned before, a lower value of $3.5 \mathrm{~km} / \mathrm{sec}$ has to be assumed for the shear velocity. A similar situation has been discussed by Press (1960) in a study of the southern California-Nevada region.

Comparison of the computed gravity values with the Bouguer anomalies (Oliver, written communication, 1964) gives a support to the appropriateness of Model 3 except for part of the Basin and Range province. The disagreement between the computed and observed values in the province reaches $80 \mathrm{mgals}$. In order to reconcile this discrepancy, a smaller density contrast between the crust and mantle and a larger contrast between the sediment and crust are required. It appears that this requirement is satisfied by the evidence which indicates low velocity materials in the sediments and in the upper mantle in this region (Eaton, 1963; written communication, 1964). The computed gravity values depend on the densities assigned for the crustal layers and the mantle and on the crustal thickness of a standard reference structure. If densities are taken from Birch's relationship $(\rho=0.77+$ $0.302 V p$, Birch, 1961), instead of the presently adopted mean values from the three relations, the densities in the crust and mantle should be 2.67 and $3.17 \mathrm{~g} / \mathrm{cm}^{3}$ respectively. These densities and the same average crustal thickness would produce a negative maximum gravity of -205 mgals under the Sierra, which is only 20 mgals more negative than the above computed value. If the calculated gravity attraction $V$ is referred to the standard section of Byerly (1939) in central California instead of the adopted average section over the present profile, all computed anomalies should be less by 20 mgals than those given in the preceding section. However, these considerations do not seem to yield such a large discrepancy between the computed and observed gravity values as given by Press and Biehler (1964) for some stations on the eastern flank of the Sierra Nevada.

A comparison of the group velocity observations made at Berkeley and Reno for Love waves from the Utah earthquake of 1962 gave support to the preferred structure (Model 3) for the present profile. To confirm this conclusion more data on both Rayleigh and Love waves need to be analyzed. If stations with long-period instruments were more closely spaced over the entire region, variations in the crustal thickness across the Sierra Nevada could be detected by the phase velocity method.

In the present study, two-dimensional analyses have been made for $P_{n}$ observations, gravity distribution and dispersion of surface waves. It should be remarked that recent seismic refraction data obtained from the Shasta-Mono Lake-China Lake profile by the U. S. Geological Survey (Eaton, written communication, 1964), 
which are not yet published, suggest a thicker crust beneath the southern Sierra than beneath the northern part. In this case, it would be necessary to combine the three kinds of information used in this study by means of a more complete threedimensional analysis.

\section{ACKNOWLEDGMENT}

I wish to express my thanks to Dr. Bruce A. Bolt for his valuable suggestions throughout this study. Dr. Perry Byerly and Dr. Otto Nuttli kindly read the manuscript and provided many suggestions. I am grateful to Dr. Howard W. Oliver and Dr. Jerry P. Eaton who kindly made Bouguer anomaly data and refraction results available in advance of publication and offered useful comments on the manuscript. Dr. Ryôsuke Satô and Dr. Thomas Turcotte also gave useful advice to the author. I am indebted to the Directors of stations who kindly supplied data.

This research was supported by Contract AF 49(638)-904 of the U. S. Air Force Office of Scientific Research.

\section{REFERENCES}

Birch, F.

1961. "The velocity of compressional waves in rocks to 10 kilobars, Part 2", J. Geophys. Res., 66 : 2199-2224.

Byerly, $\mathrm{P}$.

1938. "Comments on 'The Sierra Nevada in the light of isostasy' by A. C. Lawson", Bull. Geol. Soc. Am., 48: 2025-2031.

Byerly, $P$.

1939. "Near earthquakes in central California", Bull. Seism. Soc. Am., 29: 427-462.

Carder, D. S., and L. F. Bailey

1958. "Seismic wave travel times from nuclear explosion", Bull. Seism. Sac. Am., 48: 377-398.

De Noyer, $\mathbf{J}$.

1961. "The effect of variations in layer thickness on Love waves", Bull. Seism. Soc. Am., $51: 227-235$.

Eaton, J.

1963. "Crustal structure from San Francisco, California, to Eureka, Nevada, from seismic refraction measurements", J. Geophys. Res., 68: 5789-5806.

Evernden, J. F.

1954. "Direction of approach of Rayleigh waves and related problems", Bull. Seism. Soc. Am., 44: 159-184.

Gutenberg, B.

1943. "Seismological evidence for roots of mountains", Bull. Geol. Soc. Am., 54: 478-498.

Hamilton, R. M., A. Ryall, and E. Berg

1964. "Crustal structure southwest of San Andreas fault from quarry blasts", Bull. Seism. Soc. Am., 54: 67-77.

Healy, J. H.

1963. "Crustal structure along the coast of California from seismic refraction measurements", J. Geophys. Res., 68: 5777-5787.

Kuo, J., and J. E. Nafe

1962. "Period equation for Rayleigh waves in a layer overlying a half-space with a sinusoidal interface", Bull. Seism. Soc. Am., 52: 807-822.

Oliver, H. W., L. C. Pakiser, and M. F. Kane

1961. "Gravity anomalies in the central Sierra Nevada, California", J. Geophys. Res., $66: 4265-4271$.

Oliver, H. W., and D. R. Mabey

1963. "Anomalous gravity field in east-central California", Bull. Geol. Soc. Am., 74: 12931298. 
Press, F.

1956. "Determination of crustal structure from phase velocity of Rayleigh waves, Part I. Southern California", Bull. Geol. Soc. Am., 67: 1647-1658.

Press, F.

1960. "Crustal structure in California-Nevada region", J. Geophys. Res., 65: 1039-1051.

Press, F., and S. Biehler

1964. "Inferences on crustal velocities and densities from P-delays and gravity anomalies", J. Geophys, Res., 69: 2979-2995.

Romney, C.

1957. "Seismic waves from the Dixie Valley-Fairview Peak earthquake", Bull. Seism. Soc. Am., 47: 301-319.

Talwani, M., J. L. Worzel and M. Landisman

1959. "Rapid gravity computations for two-dimensional bodies with application to the Mendocino submarine fracture zone", $J$. Geophys. Res., 64: 49-59.

Talwani, M., J. L. Worzel, and M. Ewing

1961. "Gravity anomalies and crustal section across the Tonga trench", J. Geophys. Res., 66: $1265-1278$.

Thompson, G. A., and M. Talwani

1959. "Crustal section across California and Sierra Nevada", Bull. Geol. Soc. Am., 70: 1688.

Tsuboi, C.

1956. "Crustal structure in northern and middle California from gravity-pendulum data", Bull. Geol. Soc. Am., 67: 1641-1646.

Woollard, G. P.

1959. "Crustal structure from gravity and seismic measurements", J. Geophys. Res., 64: $1521-1544$.

Woollard, G. P. and J. C. Rose

1963. "International Gravity Measurements", Society of Exploration Geophysicists, 347: 348,368 .

SEISMOGRAPHIC STATION

UnIVERSITY OF CALIFORNIA

Berkeley, California

on leave from.

Disaster Prevention Ressearch Institute,

Kyoto University, KYoto, Japan

Manuscript received October 13, 1964. 